\title{
Način dokumentiranja disanja plućnih pacijenata na Klinici za plućne bolesti Jordanovac
}

\section{The way of documenting the breathing of patients with pulmonary diseases at the Clinical Centre for Pulmonary Diseases Jordanovac}

\author{
Kozonić Lidija', Režić Slađana² \\ 'KBC Zagreb, Klinika za plućne bolesti Jordanovac, Odjel intenzivne skrbi, Jordanovac 104, 10000 Zagreb, Hrvatska \\ 'University Hospital Center Zagreb, Clinical Centre for Pulmonary Diseases Jordanovac, Jordanovac 104, 10000 Zagreb, Croatia \\ ${ }^{2}$ KBC Zagreb, Odjel za osiguranje i unaprjeđenje kvalitete zdravstvene zaštite, Kišpatićeva 12, Zagreb, Hrvatska \\ ${ }^{2}$ University Hospital Center Zagreb, Department of quality assurance and advancement of health care, Kišpatićeva 12, 10000 Zagreb, Croatia
}

\section{Sažetak}

Uvod: Najvažniji je proces ljudskog organizma disanje. Disanje se izvodi nesvjesno i voljno, a kontroliraju ga skupine živaca koji pripadaju voljnom sustavu te skupina autonomnih živaca. Disanje ukazuje na niz poremećaja i zbog toga je važno pratiti i bilježiti disanje pacijenata u bolnici.

Cilj: Cilj je rada utvrditi način dokumentiranja disanja kod plućnih pacijenata na dvama odjelima Klinike za plućne bolesti Jordanovac.

Metode i ispitanici: Retrospektivnom je analizom sestrinske dokumentacije uključeno 60 pacijenata koji su se liječili na dvama odjelima Klinike za plućne bolesti Jordanovac. U tu svrhu izrađena je tablica u koju su se upisivali podaci vezani za dokumentiranje disanja.

Rezultati: Rezultati pokazuju da postoje razlike u dokumentiranju disanja između dvaju analiziranih odjela Klinike za plućne bolesti Jordanovac. Medicinske sestre s Odjela intenzivne skrbi u visokom postotku bilježe disanje prilikom prijema pacijenata na 0djel (87 \%). Svakodnevno se višekratno bilježi disanje u obrascu vitalnih znakova te se prati disanje putem saturacije i plinske analize arterijske krvi. Medicinske sestre s Odjela za opstruktivne bolesti pluća bilježe disanje pacijenata prilikom prijema u 53 \% slučajeva, dok se bilježenje disanja u obrascu vitalnih znakova ne bilježi, a u samo 43 \% slučajeva prati se saturacija.

Zaključak: Analizom je utvrđeno postojanje razlike u dokumentiranju disanja između dvaju odjela Klinike za plućne bolesti Jordanovac. Razlike se odnose na bilježenje disanja u sestrinskoj anamnezi prilikom prijema pacijenata na odjele, bilježenje disanja u obrascu vitalnih znakova, praćenju disanja mjerenjem saturacije i vađenjem plinske analize arterijske krvi. Rezultati pokazuju značajne razlike te upućuju na potrebu dodatne edukacije medicinskih sestara.

Ključne riječi: disanje, oblici disanja, zapisi o disanju, vitalni znakovi

Kratki naslov: Dokumentiranje disanja plućnih bolesnika

\begin{abstract}
Introduction: The most important process of the human body is breathing. Breathing is performed unconsciously and voluntarily and is controlled by a group of nerves that belong to the voluntary nervous system, as well as a group of nerves that belong to the autonomic nervous system. Breathing can indicate a serious of disturbances and it is imperative to track and record a patients' breathing upon hospital admittance.
\end{abstract}

Goal: The goal of this paper was to determine the way patients' breathing was recorded at two wards of the Clinical Centre for Pulmonary Diseases Jordanovac.

Materials and methods: Via retrospective analysis of nursing records, $60 \mathrm{pa}-$ tients that were treated at two different hospital wards of the Clinical Centre for Pulmonary Diseases Jordanovac were included. For that purpose, a table was made in which data regarding the patients' breathing was recorded.

Results: Results show that there are differences in the recording of breathing between the two analysed wards of the Clinical Centre for Pulmonary Diseases Jordanovac. A high percentage of nurses from the Intensive Care Unit record breathing when admitting patients (87\%). Breathing in the pattern of vital signs is recorded several times a day and breathing is monitored by saturation and arterial blood gas analysis. Nurses from the Obstructive lung disease ward record the patients' breathing on admission in $53 \%$ of cases, while the recording of breathing in the pattern of vital signs is not recorded, and in only $43 \%$ of cases, saturation is monitored.

Conclusion: Breathing is an important vital sign which can indicate a worsening of a pulmonary patient's condition. By analysing records, we determined a difference in the way that patient's breathing was recorded at two wards of the Clinical Centre for Pulmonary Diseases Jordanovac. The differences are visible in the nursing anamnesis during patient admittance, the recording of breathing in the vital signs form, as well as breathing monitoring via measurements of saturation and arterial blood gas analysis. Results show significant differences and point to the need for additional education of nurses.

Keywords: breathing, forms of breathing, breathing records, vital signs

Runing head: The way of documenting the breathing of patients with pulmonary diseases 


\section{Uvod}

Disanje je jedan od vitalnih znakova bez kojeg život ne bi bio moguć. Rano prepoznavanje promjena u brzini i ritmu disanja pacijentima može spasiti život ili skratiti boravak u bolnici. Zbog toga je bitno da sestre koje su stalno uz pacijente mjere disanje i bilježe ga u sestrinsku dokumentaciju te prilikom svake promjene disanja obavijeste liječnika. Navedeno je posebno važno kod plućnih pacijenata koji otprije imaju teškoća s disanjem te bi rano prepoznavanje pogoršanja disanja omogućilo pravodobno provođenje potrebnih intervencija.

Disanje ima nekoliko funkcija: unos kisika u tijelo, uklanjanje ugljičnog dioksida iz tijela, regulaciju acidobazne ravnoteže u tijelu te regulaciju tjelesne temperature [1].

Normalna frekvencija disanja u mirovanju kod odraslih osoba iznosi 12 - 18 udisaja u minuti. U nadzoru disanja sudjeluju brojne strukture disanja od perifernih receptora u karotidnim tjelešcima i plućima do viših središta u mozgu. Stoga se u tom složenom sustavu često razvijaju poremećaji koji remete normalan ritam disanja te dovode do patoloških oblika disanja.

Svaki je vitalni znak pri prvom pregledu pacijenta potrebno izmjeriti i zabilježiti, osobito ako postoje odstupanja.

Obrazac za bilježenje vitalnih znakova čini obavezan obrazac sestrinske dokumentacije [3]. U obrazac se upisuju svi vitalni znakovi prilikom prijema pacijenta na odjel (puls, tlak, tjelesna temperatura i disanje). Na odjelima se prate vitalni znakovi koji odstupaju od normalnih vrijednosti. Na Odjelu intenzivne skrbi vitalni se znakovi upisuju svakodnevno i to obično svaka 2 - 4 sata [4].

U obrascu vitalnih znakova postoji mogućnost evidentiranja frekvencije disanja i načina primjene kisika. Propisano bilježenje disanja omogućuje nam uvid u promjene koje se događaju kod pacijenta tijekom dana ili tijekom cijelog boravka.

Vitalni znakovi bilježe se u sestrinskoj dokumentaciji i preporuka je da budu zabilježeni prilikom prijema pacijenta na odjel i mjereni u pravilnim razmacima ovisno o potrebama pacijenta za nadzor vitalnih znakova. Potrebno je i dokumentirati sva njihova odstupanja od normalnih vrijednosti.

Bitna promjena u vitalnim znakovima ukazuje na promjene u stanju pacijenta koje mogu dovesti do pogoršanja stanja. Disanje, osobito kod pulmoloških bolesnika, često je prvi znak pogoršanja plućne bolesti. Rana identifikacija promjena u disanju omogućuje pravovremeno zbrinjavanje pacijenta. Promjena u brzini disanja jedan je od prvih znakova da se nešto događa u organizmu.

The National Institute for Health and Care Excellence (NICE) navodi da medicinske sestre imaju nedostatno znanje o disanju te da ne bilježe disanje tijekom prijema pacijenta u bolnicu iako za to postoji predviđeni protokol. Također je uočeno nedostatno praćenje disanja [5]. Neprepoznavanje ranih znakova pogoršanja stanja pacijenta može rezultirati lošim ishodima za pacijente. Promjene od samo 3 - 5 udisaja u minuti mogu ukazati na promjene stanja pacijenata i često su prvi znak pogoršanja stanja. To je osobito važno za pacijente koji boluju od kronične opstruktivne plućne bolesti [6].
Medicinska sestra prati disanje promatrajući brzinu, dubinu, ritam respiratornih kretanja i zvučne fenomene, po potrebi stavljajući dlan na prsni koš, slušalice ili pomoću monitora [7]. Zdrav, odrastao čovjek normalno diše kroz nos bez napora, jedva čujno od 16 do 20 puta u minuti [2]. Disanje se mjeri 60 sekundi. Moguće je izbjeći svjesnu promjenu disanja kod pacijenta tako da se nastavi mjeriti disanje odmah nakon mjerenja pulsa. Potrebno je procijeniti faktore rizika za promjenu disanja poput fizičkog napora ili stresa. Povećanu frekvenciju disanja može uzrokovati povišena tjelesna temperatura za 1 stupanj Celzijusa, i to za 4 udaha u minuti.

\section{Ciljevi rada}

Cilj je rada utvrditi dokumentiranje disanja plućnih pacijenata na dvama odjelima Klinike za plućne bolesti Jordanovac.

Specifični su ciljevi utvrditi sljedeće:

- upisuje li se disanje u sestrinsku anamnezu prilikom prijema pacijenta na odjel;

- bilježi li se disanje u vitalnim znakovima sestrinske dokumentacije;

- na koji se način bilježe pogoršanja disanja pacijenata;

- prati li se saturacija bolesnika tijekom njihova boravka na odjelu;

- prati li se plinska analiza arterijske krvi tijekom boravka pacijenta na odjelu;

- na koji se način disanje bilježi u trajnom praćenju stanja pacijenata.

\section{Metode i ispitanici}

Istraživanje je provedeno na Klinici za plućne bolesti Jordanovac 2018. godine. Ispitivanje je odobrilo Etičko povjerenstvo KBC-a Zagreb.

Retrospektivno istraživanje obuhvatilo je 60 pacijenata Klinike za plućne bolesti Jordanovac: 30 pacijenata na Odjelu intenzivne skrbi i 30 pacijenata na Odjelu za opstruktivne bolesti pluća. Za potrebe istraživanja izrađen je obrazac u koji su upisivani podaci o pacijentima (demografski podaci pacijenata) te podaci vezani za dokumentiranje disanja u sestrinskoj dokumentaciji. Podaci su prikupljeni iz bolničkog informacijskog sustava ustanove.

\section{Rezultati}

S obzirom na spol pacijenata, na Odjelu intenzivne skrbi bilo je 19 muškaraca (63 \%) i 11 žena (37\%). Na Odjelu za opstruktivne bolesti pluća od ukupno 30 pacijenata bila su 22 muškarca (73 \%) i 8 žena (27 \%). Prikaz je vidljiv na Slici 1. S obzirom na dob pacijenata, na Odjelu intenzivne skrbi bila su 4 pacijenta ispod 50 godina starosti (13\%), 12 pacijenata u rasponu dobi od 51 do 65 godina (40\%) te 14 pacijenata u dobi od 66 i više godina (47 \%). 


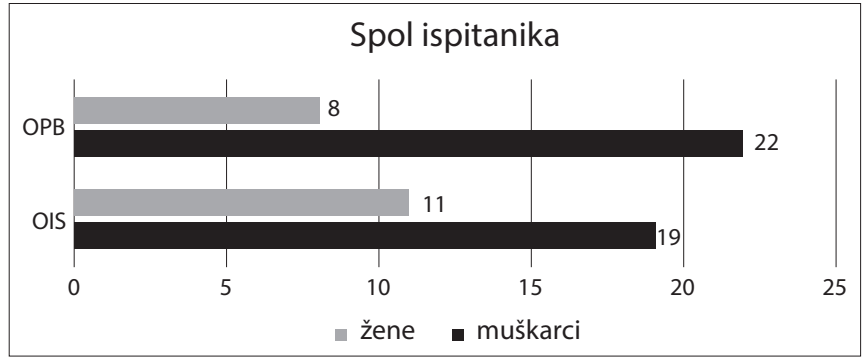

SLIKA 1. Prikaz ispitanika s obzirom na spol

$\mathrm{Na}$ Odjelu za opstruktivne bolesti pluća od ukupno 30 pacijenata, 3 su pacijenta (10 \%) bila mlađa od 50 godina, 13 pacijenata (43\%) bilo je u rasponu od 51 do 65 godina te je 14 pacijenata (47 \%) bilo starije od 66 godina života (Slika 2.).

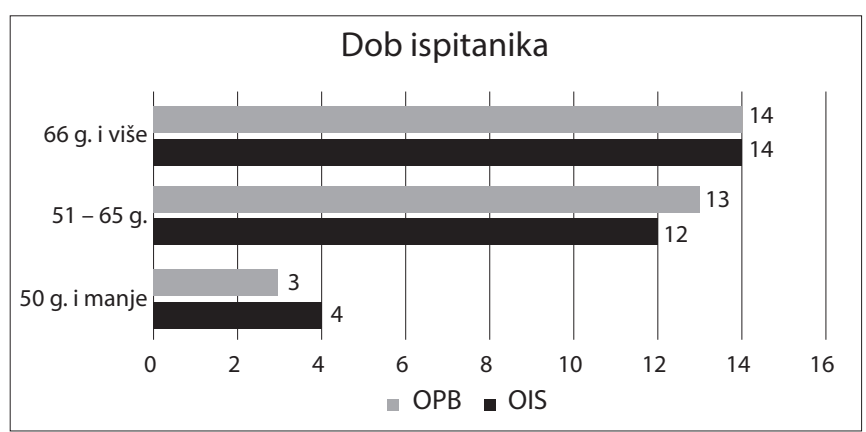

SLIKA 2. Prikaz ispitanika s obzirom na dob

S obzirom na medicinske dijagnoze pacijenata, dobiveni su sljedeći rezultati. Na Odjelu intenzivne skrbi bilo 12 je pacijenata $(40 \%) s$ kroničnom opstruktivnom plućnom bolesti (KOPB), 4 pacijenta (13\%) s globalnom respiratornom insuficijencijom (IRG), s pneumonijom je bilo 5 pacijenata (17 $\%)$, a 9 pacijenata (30 \%) imalo je druge dijagnoze.

$\mathrm{Na}$ Odjelu za opstruktivne bolesti pluća bilo je 9 pacijenata (30\%) s kroničnom opstruktivnom plućnom bolesti, 2 pacijenta (7 \%) imala su dijagnozu respiratorne globalne insuficijencije, 9 pacijenata (30\%) bolovalo je od pneumonije, a 10 pacijenata (33 \%) imalo je neku drugu dijagnozu. Prikaz na Slici 3.

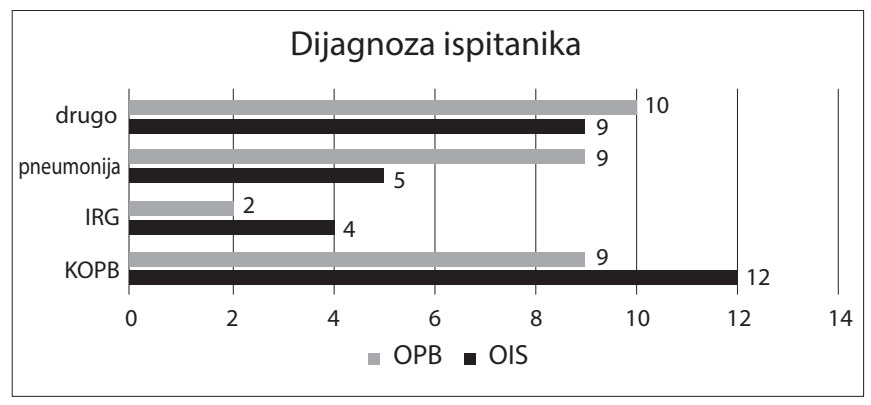

SLIKA 3. Prikaz ispitanika s obzirom na dijagnozu
Praćen je broj dana ležanja pacijenata na Odjelu. Ukupno 2 pacijenta (7 \%) boravila su manje od 3 dana, 4 - 7 dana na Odjelu je ležalo 7 pacijenta ( $23 \%), 8$ - 14 dana boravilo je 5 pacijenata (17 \%), a 16 pacijenata (53 \%) ležalo je 15 i više dana (Slika 4.). Raspon dana ležanja pacijenata na Odjelu intenzivne skrbi je 2 - 78 dana.

$\mathrm{Na}$ Odjelu za opstruktivne bolesti pluća od 30 pacijenata, 2 su pacijenta (7\%) boravila do 3 dana, 6 pacijenata (20\%) ležalo je $4-7$ dana, 17 pacijenata (57 \%) boravilo je 8 - 14 dana, a više od 15 dana na Odjelu je ležalo 5 pacijenata (16 \%). Raspon dana ležanja na Odjelu je 2 - 29 dana. Navedeno je prikazano na Slici 4.

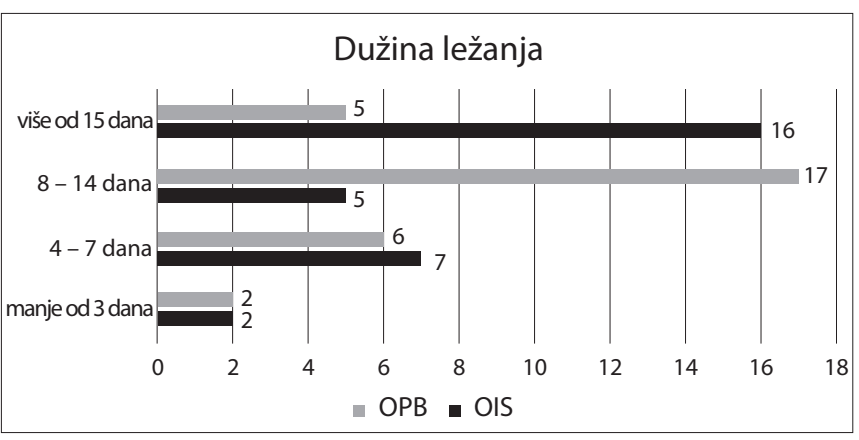

SLIKA 4. Prikaz ispitanika s obzirom na dužinu ležanja

Dobiveni podaci o bilježenju disanja u sestrinskoj anamnezi pri dolasku na Odjel intenzivne skrbi ukazuju na to da je kod 26 pacijenata (87 \%) zabilježen način disanja i broj respiracija, a kod 4 pacijenta (13\%) nije zabilježen.

$\mathrm{Na}$ Odjelu za opstruktivne bolesti pluća disanje se u sestrinskoj anamnezi bilježilo kod 16 pacijenata (53\%), a kod 14 pacijenata (47 \%) nije zabilježen način disanja.

Uvidom u obrazac sestrinske dokumentacije za bilježenje vitalnih znakova dobiveni su sljedeći podaci: na Odjelu intenzivne skrbi za svih 30 pacijenata (100 \%) zabilježeno je disanje, dok je na Odjelu za opstruktivne bolesti pluća disanje zabilježeno kod 3 pacijenta (10 \%), a kod 27 pacijenata (90\%) nije bilo zapisa o disanju u vitalnim znakovima.

Na Odjelu intenzivne skrbi vrijednost saturacije u sestrinskoj dokumentaciji bilježila se kod svakog pacijenta (100 \%), a isto tako se radila i plinska analiza arterijske krvi (PAAK) svakom pacijentu.

Na Odjelu za opstruktivne bolesti pluća vrijednost saturacije zabilježena je kod 13 pacijenata (43\%), a nije zabilježena kod 17 pacijenata (57\%). Plinska analiza arterijske krvi provjeravana je kod 24 pacijenta (80 \%), a kod 6 pacijenata (20 \%) nikad nije zabilježena.

Nadalje, na Odjelu intenzivne skrbi disanje je u trajnom praćenju stanja pacijenta (decursus) zabilježeno svim pacijentima. Vrijednosti saturacije zapisane su svim pacijentima (100 \%). Zabilježeno je da je na neinvazivnoj ventilaciji (NIV) bilo 7 pacijenata ( $23 \%$ ), mehaničkoj ventilaciji 3 pacijenta (10 \%) i na CPAP-u (engl. continuos positive airway pressure) 2 pacijenta (7\%). Da su pacijenti na nekom obliku terapije 
kisikom, zabilježeno je kod 27 pacijenata (90 \%), 3 pacijenta nisu bila ni na kakvoj potpori kisikom, a 15 pacijenata (50\%) bilo je na Venturi masci, što je također zabilježeno.

Disanje u decursusu na Odjelu za opstruktivne bolesti pluća zabilježeno je kod 18 pacijenata (60\%). Kod 4 pacijenta (13 \%) zapisana je vrijednost saturacije, kod 3 pacijenta (10\%) zapisano je da su bili na NIV-u. Na mehaničkoj ventilaciji nije bio nijedan pacijent, dok je na CPAP-u bilo zabilježeno 3 pacijenta (10\%). Također je kod 6 pacijenata (20\%) zapisano da su upotrebljavali Venturi masku. Navedeno je prikazano u Tablici 1.

TABlica 1. Zapis u decursusu o disanju

\begin{tabular}{llccc}
\hline & Zapis & OIS & OPB \\
\hline 1 & Zapis o disanju u decursusu & 30 & 18 \\
\hline 2 & Zapis o vrijednosti saturacije u decursusu & 30 & 4 \\
\hline 3 & Zapis o primjeni kisika u decursusu & & 30 & 6 \\
\hline \multirow{2}{*}{4} & $\begin{array}{l}\text { Zapis o mehaničkoj ventilaciji u } \\
\text { decursusu }\end{array}$ & $\mathrm{MV}$ & 3 & 0 \\
\cline { 3 - 5 } & $\mathrm{NIV}$ & 7 & 3 \\
\cline { 2 - 4 } & $\mathrm{CPAP}$ & 2 & 3 \\
\hline
\end{tabular}

Od 30 pacijenata tijekom praćenja, otpušteno je 18 pacijenata $(60 \%), s$ tim da su isti pacijenti najprije premješteni na bolnički odjel, a potom su otpušteni kući. U Specijalnu bolnicu za plućne bolesti i tuberkulozu Klenovnik premještena su 3 pacijenta (10\%), 3 su pacijenta (10\%) premještena u Specijalnu bolnicu za plućne bolesti, a smrtni ishod imala su 2 pacijenta (7\%). U druge ustanove (OB Koprivnica, Specijalna bolnica Krapinske toplice i OB Karlovac) premještena su 4 pacijenta (13\%).

Od ukupnog broja pacijenata s Odjela za opstruktivne bolesti pluća, njih 27 (90\%) otpušteno je kući, u Specijalnu bolnicu za plućne bolesti i tuberkulozu Klenovnik premještena su 2 pacijenta (7\%), a smrtni ishod imao je 1 pacijent (3\%). U druge ustanove te u Specijalnu bolnicu za plućne bolesti nije premješten niti jedan pacijent. Navedeno je prikazano na Slici 5.

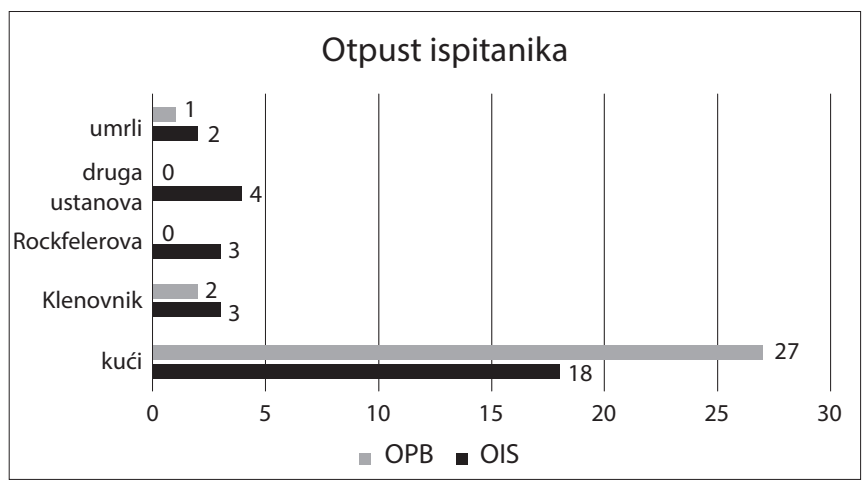

SLIKA 5. Prikaz otpusta ispitanika

\section{Rasprava}

Rezultati istraživanja pokazali su da postoje razlike u bilježenju disanja u sestrinskoj dokumentaciji na Odjelu intenzivne skrbi i Odjelu za opstruktivne bolesti pluća. Na Odjelu intenzivne skrbi u $87 \%$ slučajeva u sestrinskoj se anamnezi bilježi disanje prilikom prijema pacijenta, dok se isto na Odjelu za opstruktivne bolesti bilježi u samo $53 \%$ slučajeva.

S obzirom na to da je procjena vitalnih znakova presudan dio procjene pacijenata, zanemarivanje mjerenja respiratornog ritma zabrinjavajuće je. To mjerenje zatim služi za prepoznavanje akutnih promjena i znakova pogoršanja, a ujedno je korisno kako bi se prepoznala potreba za dodatnim terapijskim postupcima.

$\mathrm{U}$ istraživanju koje je proveo Elliott navodi se da je ključna odgovornost medicinske sestre prepoznavanje i tumačenje fizioloških abnormalnosti. Navedeno uključuje i praćenje vitalnih znakova te obavještavanje prilikom odstupanja od normale. Uspostavom sustava koji bi upozoravao medicinske sestre da je potrebno procijeniti vitalne znakove, omogućilo bi se pravodobno poduzimanje postupaka u slučaju abnormalnosti [8].

Također analizom je utvrđeno da se disanje u obrascu vitalnih znakova na Odjelu intenzivne skrbi bilježi kod svih pacijenata svakodnevno i višekratno, svaka 2 sata. Što se tiče Odjela za opstruktivne bolesti pluća, taj se podatak odnosi samo na $10 \%$ pacijenata. Obrazac vitalnih znakova obavezan je obrazac sestrinske dokumentacije i njegova je uloga svakodnevno praćenje vitalnih znakova kako bi se na vrijeme otkrilo svako odstupanje od normalnih vrijednosti i kako bi se pravodobno interveniralo. Stoga podatak na Odjelu za opstruktivne bolesti pluća ne zadovoljava, čak ukazuje na potrebu za dodatnom edukacijom te potrebom osvješćivanja važnosti bilježenja vitalnih znakova.

Creticos navodi da je prije uvođenja sustava ranog upozoravanja i novih tablica vitalnih znakova, samo $30 \%$ pacijenata na odjelu imalo jedanput zabilježen broj respiracija. Nakon godinu dana praćenja stanje se poboljšalo te je disanje imalo zabilježeno $90 \%$ pacijenata [9]. Ovdje je važno istaknuti da na Odjelu intenzivne skrbi pacijenti imaju kontinuirani monitoring te je veći broj medicinskih sestara koje skrbe o pacijentima. Unatoč tome, podatak o izuzetno malom broju pacijenata kojima se bilježe vitalni znakovi na Odjelu za opstruktivne bolesti pluća ukazuje na daljnje propitivanje tog problema.

Podaci vezani za saturaciju pokazuju da se ona na Odjelu intenzivne skrbi bilježi kod svih pacijenata, dok se na Odjelu za opstruktivne bolesti pluća taj podatak bilježi kod $43 \%$ pacijenata. Saturacija je bezbolna i jednostavna metoda kojom se brzo dobiva uvid u stanje zasićenosti krvi kisikom te se često upotrebljava na plućnim odjelima. Sam postupak mjerenja traje 1 minutu što je čini poželjnom u praćenju stanja pacijenta. Stoga je nezadovoljavajuć podatak da se saturacija na Odjelu za opstruktivne bolesti pluća bilježi tek kod $43 \%$ pacijenata. Nedostatak razumijevanja svrhe pulsne oksimetrije može ukazivati na širi nedostatak razumijevanja akutnih stanja od strane medicinskih sestara [9]. 
Plinska analiza arterijske krvi (PAAK) invazivna je metoda koja je bolna za pacijenta, ali važna u procjeni disanja jer nam daje uvid u vrijednosti plinova u krvi. Na Odjelu intenzivne skrbi podaci o PAAK-u pokazuju da se ona prati svaki dan kod svih pacijenata, dok se na Odjelu za opstruktivne bolesti pluća taj podatak odnosi na 24 pacijenta (80\%). Povežemo li podatke o PAAK-u i saturaciji, vidljivo je da je PAAK učestalija metoda praćenja stanja pacijenata. $S$ jedne strane, to je razumljivo jer nam PAAK daje uvid u razinu plinova u krvi, no s druge strane, bolan je za pacijente što se ne može zanemariti. Saturacija bi trebala biti prva metoda praćenja stanja disanja plućnih pacijenata jer ju pacijenti lakše podnose i na osnovi njezinih vrijednosti mogu se donositi odluke o potrebi za PAAK-om.

Navedeni su podaci usko povezani s primjenom kisika jer bi svaki pacijent koji se koristi kisikom, trebao biti praćen putem saturacije najmanje dva puta dnevno uz zabilježenu vrijednost disanja. Na temelju tih vrijednosti, može se učiniti PAAK. Podaci pokazuju da se pacijentima na Odjelu intenzivne skrbi primjena kisika bilježi u 90 \% slučajeva, dok se na Odjelu za opstruktivne bolesti pluća bilježi tek u $57 \%$.

Garrido navodi da je bilježenje disanja važno jer se često događa da pacijenti s neprepoznatom promjenom brzine disanja završe u jedinicama intenzivne skrbi. Također ističe da se mnogi pacijenti premještaju s bolničkog djela na Intenzivnu jer im se stanje pogorša do te mjere da trebaju neki oblik invazivne ili neinvazivne ventilacije. Na taj se način produljuje trajanje liječenja i dovodi život pacijenta u opasnost. Kao razlog tomu isiče manjkavu edukaciju medicinskih sestara koje navode da disanje nije vitalni znak i da ga nije potrebno pratiti poput ostalih vitalnih znakova. One smatraju da ga trebaju mjeriti samo onda kada je pacijent loše ili ako mu se zdravstveno stanje pogoršava [10].

Uočene su razlike u bilježenju disanja u decursusu. Na Odjelu intenzivne skrbi svim je pacijentima praćena i bilježena vrijednost saturacije te oblik terapije kisikom. Također se bilježilo ako je dolazilo do promjene u primjeni terapije kisikom. Na Odjelu za opstruktivne bolesti pluća korištenje kisika kao oblika terapije zabilježeno je kod 18 pacijenata, to jest $60 \%$. Nalazimo vrlo malo zapisa koji opisuju promjene kod pacijenta tijekom boravka. Studija Flendy pokazuje da većina medicinskih sestara samo stavi kvačicu u kućicu za disanje na sestrinskoj listi ne izmjerivši disanje [11]. Taj je podatak zabrinjavajuć s obzirom na to da promjena u brzini disanja može ukazivati na pogoršanje stanja pacijenta.

Analiza je pokazala da je na Odjelu intenzivne skrbi od 30 promatranih pacijenata, njih 18 premješteno na bolnički odjel, dok je 10 pacijenata premješteno u drugu ustanovu zbog zahtjeva za daljnjom skrbi, a 2 su pacijenta umrla. S Odjela za opstruktivne bolesti pluća 27 pacijenata otpušteno je kući, 2 su pacijenta premještena u drugu ustanovu, a 1 je pacijent preminuo.

\section{Zaključak}

Disanje je važan vitalni znak koji nam može ukazivati na pogoršanja stanja plućnih pacijenata. Analizom je utvrđeno postojanje razlike u dokumentiranju disanja između dvaju odjela Klinike za plućne bolesti Jordanovac. Razlike su utvrđene u bilježenju disanja u sestrinskoj anamnezi prilikom prijema pacijenata na Odjel. Odjel za opstruktivne bolesti pluća značajno manje bilježi disanje u sestrinskoj anamnezi nego Odjel za intenzivnu skrb.

Također postoji razlika u bilježenju disanja u obrascu vitalnih znakova. Najčešće se nadzor disanja provodio putem saturacije i plinskom analizom arterijske krvi.

Rezultati pokazuju značajne razlike i upućuju na potrebu dodatne edukacije medicinskih sestara. Predstavljeni podaci uključuju mali uzorak, stoga postoji mogućnost drugačijih interpretacija u slučaju analiza na većem uzorku.

\section{Nema sukoba interesa}

Authors declare no conflict of interest

\section{Literatura/References}

[1] Guyton CA. Fiziologijja čovjeka i mehanizmi bolesti. Peto izdanje. Zagreb: Medicinska naklada, 1995.

[2] Gamulin S, Marušić M, Kovač Z, i sur. Patofiziologija. Sedmo, obnovIjeno i izmijeneno izdanje. Zagreb: Medicinska naklada, 2011.

[3] Hrvatska komora medicinskih sestara. Pravilnik o sestrinskoj dokumentaciji u bolničkim zdravstvenim ustanovama (Narodne novine 79/11, 131/12, 71/16). [Internet]. (pristupljeno 31. 8. 2019.), dostupno na: http://www.hkms.hr/dokumenti-i-propisi/

[4] Režić S. Sestrinska dokumentacija. Zagreb: Portal e-učenje. [Internet]. (pristupljeno 28. 8. 2019.), dostupno na: https://edu.hkms.hr/course/ view.php?id=141

[5] Nursing Times. Respiratory rate 1: why measurment and recording are crucial. 2018; [Internet]. (pristupljeno 3. 9. 2019.), dostupno na: https://www.nursingtimes.net/clinical-archive/respiratory-clinical-archive/respiratory-rate-1-why-measurement-and-recording-are-crucial-26-03-2018/

[6] Nursing Times. Respiratory rate 6: the benefits of continuous monitoring.2018; [Internet]. (pristupljeno 29. 8. 2019.) dostupno na: https://www.nursingtimes.net/clinical-archive/respiratory-clinical-archive/respiratory-rate-6-the-benefits-of-continuous-monitoring-29-10-2018/

[7] Šepec S i sur. Standardizirani postupci u zdravstvenoj njezi. Zagreb: Hrvatska komora medicinskih sestara, 2010.

[8] Elliott M. Why is Respiratory Rate the Neglected Vital Sign? A Narrative Review. International Archives of Nursing and Health Care: 2016; [Internet]. (pristupljeno 3. 9. 2019.), dostupno na: https://clinmedjournals.org/articles/ianhc/international-archives-of-nursing-andhealth-care-ianhc-2-050.pdf

[9] Cretikos MA, Bellomo R, Hillman K, Chen J, Finfer S, Flabouris A. Respiratory rate: the neglected vital sign. PubMed, 2008; [Internet]. (pristupljeno 30. 8. 2019.), dostupno na: https://www.ncbi.nIm.nih.gov/ pubmed/18513176

[10] Garrido D, Assioun JJ, Keshishyan A, Sanchez - Gonzales MA, Goubran B. Respiratory Rate Variability as a Prognostic Factor in Hospitalized Patients Transferred to the Intensive Care Unit, Cureus; 2018: [Internet]. (pristupljeno 29. 8. 2019.), dostupno na: https://www.ncbi. nlm.nih.gov/pmc/articles/PMC5866112/

[11] Flenady T, Dwyer T, Applegarth J. Accurate respiratory rates count: So should you! Australasian emergency care, 2017; 20 (1) [Internet]. (pristupljeno 2. 9. 2019.), dostupno na: https://www.ausemergcare.com/ article/S1574-6267(16)30060-X/fulltext 